\title{
DfA Products and Services from a User Perspective to Facilitate Life at Home for People with Cognitive Impairments
}

\author{
Claes Tjäder \\ Swedish Handicap Institute (SHI) \\ Sorterargatan 23, SE 16215 Vällingby, Sweden \\ claes.tjader@hi.se
}

\begin{abstract}
Supportive technology is expected to facilitate life at home for people with cognitive impairment. To study the usability of a number of supportinstallations in ordinary homes a three-year project was launched in Sweden. Three sites, each planned to comprise some twenty participants about sixty years of age and upwards, suffering either from a cognitive impairment such as an acquired brain injury or other forms of cognitive impairments, have been engaged. One goal was to acquire knowledge and experience about technical support, their appropriateness and adaptability to the users and to the organisation supporting them. Another goal was to develop and test supportive technology and a third goal was to explore ways to the market for Design for All products which are necessary for some but useful to most of tenants. The housing companies played an important role for the development of the project and the way to the market, as many technical aids basically are parts of the physical building structure.
\end{abstract}

Keywords: Supportive technology, Design for All, cognitive impairment, independent living, housing companies.

\section{Introduction}

A three-year project has been launched addressing people with cognitive impairments residing in their own homes. Supportive technology is to be applied in order to offer these people a safer and a more independent life to the benefit for themselves, their carers and their relatives. The project - Technology support at Home (Hemma med IT is the Swedish Acronym) - was initiated by the Swedish Ministry of Social Affairs and it is managed by the Swedish Handicap Institute (SHI). The original budget for the project comprised about 1,2 million Euro. Additional funding for technical development has been raised during the project period. The Competence Fund of the City of Stockholm has contributed. Research aspects associated to some perspectives of the evaluation is funded by The Swedish Formas Research Council. The Royal Institute of Technology in Stockholm is engaged as external evaluator of the project [1]. 


\section{Background}

In line with the European Commission's Work Programme eInclusion for 2005-2006 also this Swedish project aims to provide input to meet the challenges of an ageing population, including the maximisation of user involvement. This project will hopefully provide information and guidance as well as it will provide a basis for future decision making among different stakeholders in EU and elsewhere when it comes to the question on how to implement new technology with the aim to promote independent living among vulnerable people [2].

Home care of older people is an important issue. Caring for people in old age has always been an important objective of social systems. How to ensure the social inclusion of older people will be an increasingly significant challenge. Increased life expectancy is one of the great achievements of the 20th century; we want to ensure that the majority of the extra years can be spent in health and independence. This project put focus on the IST objective to develop intelligent systems that empower persons with disabilities and ageing citizens to play a full role in society and to increase their autonomy.

Changes in demography is a result of a successful policy resulting in longer life expectancy. Providing services to a growing group of elderly people is of increasing concern.

As people live longer, as a result of a successful social policy, the demand on society's resources to meet their individual needs increases. During the coming 10 years the number of elderly over 65 years of age will increase with $27 \%$ while the increase last 10 years was limited to $1 \%$ in Sweden. This dramatic increase in the number of elderly is very much also a business opportunity for the company sector. The challenge is to maintain or increase quality of life by introducing supportive technology for people with lacking abilities when it comes to physical and cognitive abilities.

\section{Increased Quality of Life with Technology Support - A Potential to Explore}

Elderly people and others with special needs want to stay in their normal environment, in their own home, where they have a closeness to friends and relatives, as long as possible. Several questionnaires have shown this very clear. In spite of the wishes of older people to remain in their habitual environment for both health care and ordinary care, the debate is often focused on elderly's need of special living institutions. In many cases older people and more often, their relatives need the assurance and comfort of the person being safer rather than just comfortable. The sad fact is that today there is no supply of prepared, easily comparable technical "coherent solution" which make an ordinary living to a comparable alternative with health care institutions or institutional living for elderly patients and the responsible municipalities or local government agencies.

Not only technology and care matter; an equally important question is how accessible the apartments are adapted to care, aided by new technology. In addition, it is important to understand how the service delivery chain can be organised in order to meet the requirements satisfying quality criteria. It is a widely spread opinion that the 
information and communication technologies (ICT) have the potential to compensate for the lack of resources in the caring professions without inferring a lower quality of care. At the same time it is important to underline that personnel can not be replaced by technology but supported. Sometimes there is a reluctance to before or in the beginning of an introduction of new technology. Our experience is that when personnel and users discover the potential with new supportive technology, reluctance and fear often are turned into interest and acceptance. User acceptance is necessary if you want to have a sustainable autonomous living for elderly and people with disabilities.

It is not foremost an expansion of special institutional apartments that are needed, the most important thing is to develop and adapt the present and future housing supply to vulnerable peoples needs, that is the general policy at the moment in my country.

"A growing number of older people are living in houses that do not correspond to their specific needs. The expected increase in the older population poses serious challenges to national housing policies. It has been argued that the main approach should be to support living at home for as long as possible, also allowing people to make a positive choice to move into more convenient or appropriate accommodation as they age. This being the case, more attention needs to be paid to ensure that homes are accessible, convenient and safe, and are capable of meeting the needs of residents with declining mobility." (The Social Situation in the European Union 2000, p.94, European Commission Directorate-General for Employment and Social Affairs).

According to the Commission Green Paper families will not be able on their own to solve the matter of caring for these people, however dependent or independent they are. The improved health profile of "younger elderly" generations holds out the hope that the elderly of the future will remain self-sufficient for longer times, and that they wish to remain in their homes as long as possible. High-intensity care will be increasingly concentrated towards the end-of-life period. Nevertheless, it seems that there will also be more people than today who will need such high intensity care in ordinary homes as a result of reduction of beds in hospitals and institutions.

Today there are supportive technologies that could solve a lot of problems and meet the needs of people, relatives and staff, but unfortunately they are not used.

Why are they not used? There are many reasons, ranging from the fact that the users do not feel involved, difficult and indistinct supply systems, to the lack of knowledge competence, and training, as well as a misplaced fear that costs will be high.

One of many approaches would be to develop the potential for new technologies supporting older people, both directly (for those 80+) and indirectly (by facilitating the caring tasks for elderly workers i.e. those 55-64) and for the younger proportion of the retired population (65-79). The complexity has to be considered; there are many obstacles for introduction of supportive technology in care sector. Many ask why it takes so long time.

A key issue is that organisations involved in ICT-care and telemedicine have to be involved. There is a huge gap today between on one hand those responsible for development and providers of products and services and on the other hand users and personnel in care sector.

Currently there is much research about the contribution of technology to elderly care in institutions and at home. Several European projects have been focused on independent living. Amongst other things, safety alarms, smart sensors and remotely monitored devices have been developed, installed and investigated. 
SHI will in the coming four years be involved in a new EU project on Mainstreaming on Ambient Intelligence (MonAmi), the project will demonstrate how accessible and useful services can be delivered in mainstream systems and platforms to elderly people and persons with disabilities [3].

Also on national level a variety of research and development projects have been initiated in Sweden and other countries in EU that in various ways investigate the possibilities for elderly people with acquired brain injuries to remain in their own homes.

These projects have clearly stated that the technology is there! Now it is a matter of implementation and a strategy for implementation.

\section{Technology Support at Home - A National Project ${ }^{4}$}

Three site projects have been linked together within a framework. The Swedish Handicap Institute has been the co-ordinator of the whole undertaking. In this presentation the broad lines will be outlined.

The project has the purpose to facilitate for people with cognitive impairments to remain at home maintaining a high quality of life, avoiding a transfer to special institutions apartments.

The intention has been to support people with a cognitive impairment to make it possible remain an active person. Making it possible for the user to be part of society, follow and interact with the outside world.

Technology Support at Home was initiated by the Swedish Handicap Institute and the Swedish Disability Federation, and it was jointly financed by the Swedish Inheritance Fund, three municipalities and three public housing companies. The project started in May 2004 and runs for three years.

The main reference is to persons at the age of 60 or elderly and who experience obvious problems in their daily lives due to documented cognitive impairments such as persons suffering from external injuries or strokes or Alzheimer's disease.

The technology to be applied varies from person to person, though some supportive technologies are more common.

One of the objectives of the project is to establish co-operation between the different actors involved and to find a sustainable structure for participation. This depends significantly on the complicated co-ordination between the responsible caregiver, often the elderly services of the municipality sometimes in combination with health care sector, and the housing company, which hirers out and runs the flats. It should though be stated that it was also found that some of the users in the project did not, before the project, have any contact with the social or health care sector. They managed on their own thanks to an informal support from relatives and friends.

\section{Cognitive Impairments - What Do We Mean?}

The cognitive impairments vary, depending on trauma or disease. Their hampered functions may fluctuate over the day or week. Common cognitive problems are as follows: 
- memory loss, especially episodic memory,

- psychic endurance and lack of initiative,

- attention and concentration,

- communication, handling phones and remote controls,

- time management,

- learning integration, e.g. difficulties to adjust to change,

- inability to perform movement of some complexity such as an inability to handle articles for everyday use.

\section{What Do Partners Want? Win-Win-Situation!}

The stated goal was to collect evidence based knowledge about products, services and activities that can provide a more secure and easy way of life for older persons with cognitive impairments, who are still living in their own homes.

All stakeholders' different expectations were stated. The starting point was to establish a situation where all stakeholders are winners.

The perspective of the individual is crucial, the person with cognitive impairment in his or her living situation, need of care and social context must be defined.

The technology perspective, the appropriateness, the availability and the functionality of it was, of course, important.

Another issue was the caring perspective, which relates to the caring staff and how it can adapt to new technique and services built upon it.

A crucial component of the whole delivery chain is the organisational perspective. It encompasses the caring chain, the support, and the maintenance and quality assurance of the functionality of technology and services over time. A viable situation was to be developed where the caring organisation, the housing company and the technology provider are to find viable procedures for effective co-operation.

The housing companies' prime task is to construct and operate housing premises as efficiently as possible related to cost. Already before the housing companies meet these people with cognitive impairments. A study was made in the beginning of the project where it was stated that the lack of appropriate support ended up in incidents of all kinds such as flooded bathrooms or kitchen, fire, unlocked doors resulting in intrusion of unknown people in the buildings. Additional costs due to special measures necessary for the housing of persons with special needs should be covered, from the housing company's perspective, by the authorities responsible for the proper care of these persons. This includes not the least a viable business model from which the individual as well as the society will benefit.

Finally a societal perspective and a cost-benefit perspective addressed the long term effects based in particular on the aforementioned demographic development and on the economic values of the outcome.

\section{Technology Support}

Focus has been on security, safety, communication and structure of the day. The technology to be applied assists cognitively disabled persons in many different ways with related functions in the daily life. 
Technology envisaged are functions like computerised memory aid, go-away-lock (i.e. a lock that will turn off all electricity connected to household appliances like, toaster, stove, iron, water boiler and more), an intelligent key (a key with a display showing whether the door was locked when the person left the apartment), different alarms (activity driven, fall detection, over-heated stoves etc.) and various forms of communication systems. The choice of technology and applications of the three sites have been open but there has been an ambition to harmonise.

\section{Objectives}

The overall objectives of the entire project were:

- to increase knowledge about what products, services and actions could contribute to realise a more independent and safer living for older persons with cognitive disabilities in their own homes,

- to increase the knowledge of how to deploy supportive products aimed at people with a cognitive disability. Target groups are on the one side the users/older people themselves, healthcare personnel, paramedics, social workers; and on the other side, housing site staff, who meet the tenants/older people in their daily work.

Informal carers, relatives and friends were to be involved in so far as they already were engaged with the users/tenants.

Co-operation between different responsible bodies were regarded as a key factor in the quality of delivery. It was esteemed that this approach also would affect the costs. Cost-efficiency is a necessity, otherwise only a few of those in need of the technology will be offered it. These and other aspects are being evaluated by the Royal Institute of Technology [5].

\section{Supportive Technology - Future DfA Products}

In the following a number of products and services will be listed.

Installations have been chosen from a user perspective. (Installations that normally today, in Sweden, cannot be prescribed by an occupational therapist, though the project aims to change the present structure for prescribing technical support for independent living.)

Visitor validation unit with video and sound - Constitutes a display with image and sound who is at the entrance door (or door of the apartment). The image can be connected to the TV set. More indoor displays could be possible.

Reminder panels of different kinds - The panel indicates if doors and windows are locked, and if other functions are on/off (stove, cooker, etc.)

- Go out lock - Deactivates different functions in the home (electricity outlets, water supply, open locks, etc.) when the door is locked with the key.

- Intelligent key - Type of electronic key, indicating if locking took place when the tenant/user left the home. 
- Cognitive-oriented assistive technology that today more regularly can be prescribed by authorised personnel in Sweden.

- Reminder clock - Programmable speaking clock with alarm and reminder

- Big picture phone - Phone with picture buttons activating a call to the person pictured.

- Pocket memory - Different kinds of small devices for recording alarms and reminders.

- Do not forget calendar - An electronic calendar displaying the correct day and time.

- Cognitive-oriented assistive technology that not always can be prescribed in Sweden today.

- Carecall - On-button cellphone with pre-programmed numbers. This device makes it possible for relatives/carers to support.

- Locator - Small emitters attached to devices to be identified by a remote control which helps users to find lost things in the home.

- Medication reminder - Alarms for medication and offers correct dosage until it is taken. Could also send an alarm in case medication intake is missed.

- Talking labels - small recorders fit for tins, parcels and cans. By pressing the button it says: 'this is your heart medication - take one when you feel short of breath and then phone your carer'.

- Door speaker - a device that starts a pre-recorded message when going out.

Beside all these above listed other measures could be home adaptations, including adaptations of bathrooms and kitchens.

The projects belief is that several products or technical support services used in this project could be used by a broad segment of ordinary consumers/tenants. This would also mean that products initially designed more or less as assistive device technology could be broadened to main stream market by using the concept Design for All. Of course this would also imply a design process normally used when it comes to ordinary house hold products.

The installations at the three sites have all the time also been available at demonstration apartments at the test sites and in conjunction with the facilities of SHI - the demonstration apartment SmartLab. Some of the installations have also been filmed. In a short time they will be available on the home page of the Swedish Handicap Institute [6].

\section{DfA and Users Needs}

As the project addresses a vulnerable group, it was essential that long and complicated procedures were to be avoided. The handling of the equipment by the care-taker (and the staff) should be user friendly.

The documentation had to be adapted to the real ability of the users. Finally, for tenants/users it has been shown that motivation is fundamental if they are to accept new technique and to use it voluntarily. They have to understand why and get enough time to adapt to it. 
Other studies made concerning elderly and usage of new technology it is demonstrated that elderly are willing to make use of new technology if they can identify a clear benefit from usage of the product/service [7].

A challenge for the project has been to participate in a development process of new technology together within an environment strongly characterised by a caring perspective on people with reduced cognitive capabilities.

Occupational therapists have been local project leaders at each site. From a method point of view DfA has been used as the base line. By introducing the applications for people with cognitive disabilities the project has chosen a difficult target group for evaluation of benefits. If it is shown that the target group can make use of the products/services a broader market is also available for housing companies within the coming years as a result of the demographic change.

The Design for All concept has had priority over the Assistive Technology and Adaptable Design concepts. The ranking indicated below is fundamental.

1. device/products/services should be produced so they can be used by as many persons as possible (the Design for All approach)

2. If this is not possible (for technical, safety or other highly significant reasons),.the product can be used in combination with assistive devices. (the Adaptable Design approach)

3. If neither 1. nor 2. are possible, the following could prevail; persons that are excluded should use the product/service under certain restrictions or must be excluded. (the Assistive Technology approach)

As the project aims to contribute to deployment of mainstream products this strategy has been crucial. Alternative a) has been in focus in the project.

\section{How Is the Effect Measured/Evaluated?}

The direct observations of the tenants/users behaviour and relationship to the installed technical equipment have been recorded by the regular staff during scheduled periods for at least four occasions of the three-year project. The qualifications of the staff that have been responsible for the interviews and the observations are important, as well as their instruction prior to each observation period. It has also been of importance to know the staff's attitudes to changes when simultaneously involved in the implementation.

An external evaluation has been executed, run by the Royal Technology Institute in Stockholm. The outcome of this external evaluation is a benefit assessment for all actors involved.

\section{Implementation - Follow-Up}

In 2006 a group was established constituted by housing companies, those already members of the project and some others and the national organisation of SABO - the Swedish Association of Municipal Housing Companies (the organization of the 
municipal housing companies in Sweden) [8]. The aim was to facilitate the implementation phase. The idea was to already in advance of the finalisation of the project present some activities and results. By doing so we made it possible to look into the aspects of the housing companies. Contacts have also been established with an organisation dealing with procurement on behalf of housing companies, the organisation is member of SABO. The idea was to investigate how to procure technical support for tenants on a larger scale. Marketing and financing of these installations will of course have to be dealt with, though these aspects finally is in the hands of the individual housing companies, sometimes in conjunction with societal financial schemes.

\section{Final Report in 2007}

The project is still in progress and is scheduled for completion in mid-2007. Results, so far, should then be considered as preliminary. However, the results are positive both when it comes to the technology support and the organisational experiences, i.e. information on the introduction of supportive technology in the homes of older people suffering from cognitive impairments.

All the solutions have been based on the needs of the users themselves. The aim is to speed up the development and usage of technical devices that can increase the quality of life for both the users and their relatives. The project has used practical solutions to show how technical solutions can contribute to increased independence and comfort.

The idea is also to spread awareness of the opportunities created by this new technology among decision-makers in the municipalities and county councils, housing companies and staff within home care and primary healthcare services.

Special development grants have been available during the project time to promote the development of knowledge, methods, products and services. Municipalities, county councils, staff groups, disability organisations, companies, etc. have been invited to apply for these grants. A comprehensive report from all involved partners will be available in 2007.

At the time of the HCI 2007 results will be available from the project.

\section{Notes}

1. The Royal Institute of Technology in Stockholm, Architecture. Agreement in (2004)

2. European Commission, http://ec.europa.eu/index_en.htm

3. www.hi.se; http://www.hi.se/templates/Page__2339.aspx

4. http://www.hi.se/templates/Page__1786.aspx

5. Molina, G., Petterssonb, C., Jonssonc, O., Keijera, U.: Living at Home with Acquired Cognitive Impairment - Can Assistive Technology Help? (An article in process in special edition on Technology in Dementia Care of the publication Technology and Disability)

6. www.hi.se (SmartLab)

7. Government Committee (2003), http://www.regeringen.se 
8. SABO is the organization of the municipal housing companies in Sweden. SABO is the biggest organization on the Swedish housing market. In: The approximately 300 companies affiliated manage some 830.000 dwelling units. This is $20 \%$ of the total housing stock in Sweden and about one third of all dwelling units in multi-storey houses. Altogether 1,4 milion people live in SABO homes.

The size of the SABO companies varies considerably. More than $60 \%$ have $500-$ 5.000 dwellings. The largest SABO company owns and manages some 50.000 dwellings. $\mathrm{SABO}$ provides expertise in different fields, exchanges experience between its members and cooperates with national authorities and organizations. SABO also arranges conferences and takes on consultancy assignments. (www.sabo.se) 